\title{
Clinical characteristics and risk factors of human leptospirosis in Argentina (1999-2005)
}

\author{
N.B. Vanasco ${ }^{\mathrm{a}, \mathrm{b}, *}$, M.F. Schmeling ${ }^{\mathrm{a}}$, J. Lottersberger ${ }^{\mathrm{b}}$, F. Costa $^{\mathrm{c}}$, A.I. Ko ${ }^{\text {c,d }}$, H.D. Tarabla ${ }^{\mathrm{e}}$ \\ a Instituto Nacional de Enfermedades Respiratorias (INER “Dr. E. Coni”), Administración Nacional de \\ Laboratorios e Institutos de Salud (ANLIS “Dr. Carlos G. Malbrán”), Santa Fe, Argentina \\ ${ }^{\mathrm{b}}$ Facultad de Bioquímica y Ciencias Biológicas, Santa Fe, Argentina \\ c Instituto Gonçalo Moniz, Fundação Oswaldo Cruz, Salvador, Brazil \\ ${ }^{\mathrm{d}}$ Division of International Medicine and Infectious Disease, Weill Medical College of Cornell University, NY, USA \\ e INTA, Rafaela, Argentina
}

\section{A R T I C L E I N F O}

\section{Article history:}

Received 13 March 2008

Received in revised form 23 April 2008

Accepted 23 June 2008

Available online 12 July 2008

\section{Keywords:}

Leptospirosis

Epidemiology

Risk factors

Microscopic agglutination test

Rural transmission

Argentina

\begin{abstract}
A B S T R A C T
There is scarce data on the burden of leptospirosis and its epidemiological characteristics in Argentina. This study aimed to evaluate distribution of leptospirosis cases and identify risk factors for the disease during national laboratory-based surveillance. From January 1999 to December 2005, 812 suspected cases were referred to the national reference laboratory, of which 182 and 463 had respectively, laboratory confirmed and unconfirmed diagnosis of leptospirosis. The diagnosis of leptospirosis was discarded in 167 cases. The most prevalent presumptive infecting serogroup was Icterohaemorrhagie followed by Pomona, Ballum and Canicola. The majority of cases occurred during the worm and rainy months. Confirmed cases were predominantly adults and males, who presented with fever, headache and myalgias. Severe clinical manifestations included jaundice and acute renal insufficiency. Conjunctival suffusion, a hallmark clinical sign of leptospirosis, was found in 55\% of confirmed cases, and $43 \%$ of the cases with discarded diagnosis $(p=0.036)$. After multivariate analyses, age $>30$ years $(\mathrm{OR}=2.16 ; 1.05-4.41)$, occupation in a rural setting $(\mathrm{OR}=3.41 ; 1.45-8.06)$, contact with contaminated surface water $(\mathrm{OR}=2.17 ; 1.01-4.68)$, and contact with floods $(\mathrm{OR}=4.49 ; 1.17-17.25)$ were significantly associated with leptospirosis. In conclusion, although activities associated with rural occupations remain important risk factors in Argentina, exposures occurring during flooding events have emerged to be the major risk factor for leptospirosis.
\end{abstract}

(c) 2008 Elsevier B.V. All rights reserved.

\section{Introduction}

Leptospirosis caused by spirochetes of the genus Leptospira, has a worldwide distribution and is acquired through either direct or indirect contact with urine of infected animals (Bharti et al., 2003; WHO, 2003; McBride et al., 2005). There is a wide spectrum of human disease associated with leptospirosis, ranging from subclinical infections to severe multi-organ failure associated with high mortality (Farr, 1995; Bharti et al., 2003; McBride et al., 2005). The incidence of disease is highest in humid and warm climates (Farr, 1995; Levett, 2001). The occurrence of seasonal outbreaks of leptospirosis following floods is frequent in Central and South

\footnotetext{
* Corresponding author at: Instituto Nacional de Enfermedades Respiratorias (INER “Dr. E. Coni”), Administración Nacional de Laboratorios e Institutos de Salud (ANLIS “Dr. Carlos G. Malbrán”), Blas Parera 8260, Santa Fe 3000, Argentina. Tel: +54 342 4892830; fax: +543424892830

E-mail addresses: bibi_vanasco@hotmail.com, jlotters@fbcb.unl.edu.ar (N.B. Vanasco)
}

America (Levett, 2001; Vanasco et al., 2000b, 2002, 2004; AAVLD, 2002).

In Argentina, leptospirosis was first recognized and reported in humans in 1915 in the Province of Santa Fe (Cacchione et al., 1975). However, there is limited data on the current disease burden of leptospirosis in Argentina. Furthermore the factors influencing transmission of leptospirosis in this country is not well understood (AAVLD, 2002). The reported incidence of leptospirosis is highest in regions which have access to laboratories which perform serologic confirmation with the microscopic agglutination test. In fact, the highest incidence rates for leptospirosis in Argentina are found in provinces of Buenos Aires and Santa Fe, which have established reference centres for diagnosis (AAVLD, 2002). To date, there has been little information for national laboratory-based surveillance. In this study, we describe the findings of surveillance for leptospirosis in Argentina, which was conducted by national reference laboratory in Santa Fe from 1999 to 2005. In addition to examining the burden of leptospirosis in Argentina, we evaluated the clinical presentation of cases and risk factors for acquisition of the disease. 


\section{Materials and methods}

\subsection{Laboratory-based surveillance}

Samples and epidemiological information from suspected cases of leptospirosis from Argentina are referred to the Leptospirosis Laboratory of the "Instituto Nacional de Enfermedades Respiratorias (INER)" in Santa Fe, Argentina. This reference centre receives samples from almost all provinces in Argentina. However, few samples were received from Buenos Aires, because this province has its own regional reference laboratory.

In addition to serum samples, a surveillance form is sent for all suspected patients which contains the data on demographics, clinical presentation (symptoms, clinical signs and complications), routine clinical laboratory findings (complete blood cell count and differential, serum bilirubin and transaminases and indicators of renal function), and history of risk exposures prior to onset of illness (occupation, contact with rodents, dogs and livestock) and exposures to contaminated environments such as flood, river or sewage water. Serum samples were collected at different stages of illness which included early acute-phase illness ( $<10$ days after onset of symptoms), late acute-phase illness (10-25 days) and convalescent-phase illness ( $>25$ days) (Vanasco et al., 2007). Serum samples were stored at $-70^{\circ} \mathrm{C}$ once they were received.

\subsection{Serologic confirmation of leptospirosis and definitions}

The microscopic agglutination test (MAT) was performed using standard procedure, to evaluate laboratory-confirmed leptospirosis (Faine, 1982; WHO, 2003). A panel of 12 live reference strains were used as antigens which represented the following 11 serogroups: Australis, Autumnalis, Castellonis, Canicola, Grippotyphosa, Icterohaemorrhagiae, Hebdomadis, Pomona, Pyrogenes, Tarassovi, and Sejroe. Samples were defined as serum positive for MAT titre $>1: 50$, in concordance with national surveillance guidelines for Argentina (AAVLD, 1994). The presumed infecting serogroup in confirmed cases was considered to be the serogroup against which highest MAT titres were directed (Vanasco et al., 2000b).

Cases with confirmed leptospirosis was defined as having clinical presentation and laboratory findings compatible with the disease (leukocyte counts $>8000 / \mathrm{mm}^{3}$ with $>70 \%$ of neutrophils in the differential, and either (a) a fourfold or greater rise in MAT titres between two or more serum samples from different stages of the illness or (b) $\geq 1: 200$ MAT titre in one or more serum sample. Cases with unconfirmed leptospirosis were defined as having a clinical diagnosis of leptospirosis, but did not have laboratory criteria for confirmed leptospirosis. Cases with a discarded diagnosis of leptospirosis were defined as having: (a) an initial suspicion of leptospirosis but subsequently had a confirmed diagnosis for a disease other than leptospirosis, or (b) clinical laboratory findings which are less likely to be compatible with leptospirosis (leukocyte counts
$<8000 / \mathrm{mm}^{3}$ with $<70 \%$ of neutrophils in the differential) and a negative MAT titer $(<1 / 50)$ in samples collected in different late-acute or convalescent-phase of the illness.

\subsection{Statistical analysis}

Proportions and mean \pm standard deviation (S.D.) of case characteristics were calculated for the descriptive analysis. The chi-squared test and Student's $t$-test was used to determine significant $(P<0.05)$ differences between patient groups with respect to presumed infecting serogroup, clinical signs and symptoms and clinical laboratory findings and risk exposures. A case-control analysis was performed to evaluate risk exposures associated with leptospirosis. Case subjects were those with confirmed leptospirosis. Control subjects were those who had a discarded diagnosis of leptospirosis. Children were excluded from analyses of occupational or work-related data. Odds ratio and 95\% confidence intervals (CI) were used to estimate the association of exposures with the risk for leptospirosis. Logistic regression was performed to identify independent risk associations among exposures which were identified to be significant univariate risk factors. A stepwise backward elimination approach was used to obtain the best-fit model. Maximum likelihood with a convergence criterion of 0.01 for a maximum of 10 interactions was used for estimation of model parameters. All analyses were performed using Statistix 7.0.

\section{Results}

\subsection{Surveillance}

From January 1999 through December 2005, 812 suspected cases were referred to the national reference laboratory. Of these, 182 (22\%) and 463 (57\%) had respectively, a confirmed and unconfirmed leptospirosis. The diagnosis of leptospirosis was discarded for 167 (21\%) of the suspected cases. Among the 182 confirmed cases, the presumptive infecting serogroup was $L$. interrogans serogroups Icterohaemorrhagie (57 cases, 31\%) and Pomona (27, 15\%), L. borgpetersenii serogroup Ballum (25, 14\%), L. interrogans serogroup Canicola (18, 10\%), L. borgpetersenii serogroup Sejroe (8, $4 \%$ ) and Tarassovi $(4,2 \%)$. Highest titres were directed against multiple serogroups in 43 (24\%) confirmed cases.

During the 7 -year period, $76 \%$ of cases occurred from midSummer to the end of the Fall, in coincidence with warm and rainy weather. Surveillance identified two outbreaks in Eldorado, Misiones, on 2001 and Santa Fe City, on 2003. They occurred after unusually high levels of rainfall and flooding respectively (Fig. 1). On the 2001 outbreak, the highest number of cases occurred during the Fall (March and April) after a period of heavy rain on the previous January. Meanwhile, on the 2003 outbreak, the peak occurred on the end of the Fall (May) following big floods on the previous April.

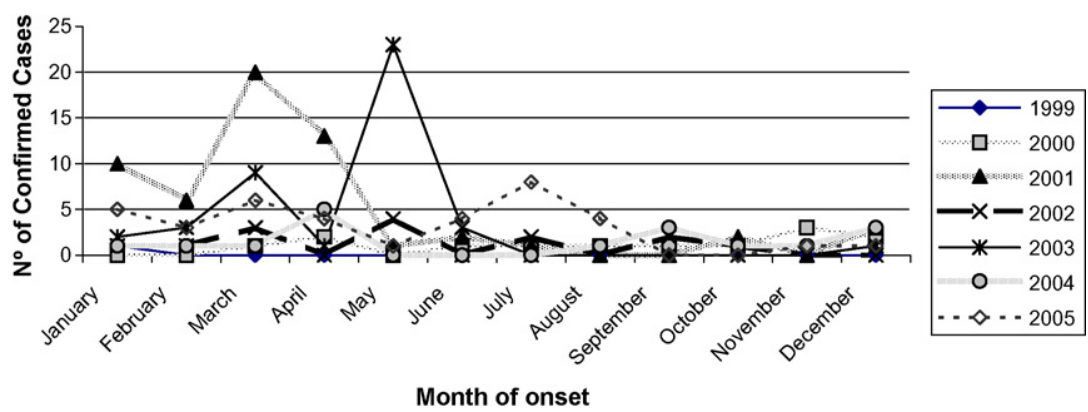

Fig. 1. Monthly distribution of 182 confirmed cases of leptospirosis, Argentina (1999-2005). 
Table 1

Clinical presentation and laboratory findings of cases with confirmed and discarded diagnoses of leptospirosis from national surveillance in Argentina, 1999-2005

\begin{tabular}{|c|c|c|c|c|c|}
\hline \multirow[t]{2}{*}{ Characteristics } & \multicolumn{2}{|c|}{ Confirmed diagnosis } & \multicolumn{2}{|c|}{ Discarded diagnosis } & \multirow[t]{2}{*}{$P$-Value } \\
\hline & No. responses & No. positive or mean \pm S.D. & No. responses & No. positive or mean \pm S.D. & \\
\hline \multicolumn{6}{|l|}{ Clinical findings } \\
\hline Fever & 139 & $131(94.2)$ & 148 & $108(73.0)$ & $<0.000$ \\
\hline Headache & 136 & $118(86.8)$ & 143 & $97(67.8)$ & $<0.000$ \\
\hline Myalgia & 134 & $105(78.3)$ & 147 & $93(63.3)$ & 0.006 \\
\hline Jaundice & 134 & $67(50.0)$ & 150 & $51(34.0)$ & 0.006 \\
\hline Conjunctival suffusion & 130 & $71(54.6)$ & 143 & $60(42.9)$ & 0.036 \\
\hline Respiratory symptoms & 125 & $28(22.4)$ & 143 & $59(41.2)$ & 0.001 \\
\hline Renal insufficiency & 116 & $52(44.8)$ & 129 & $29(22.5)$ & $<0.000$ \\
\hline Haemorrhage & 109 & $18(16.5)$ & 131 & $16(12.2)$ & 0.341 \\
\hline Meningeal signs & 123 & $16(13.0)$ & 138 & $16(11.6)$ & 0.606 \\
\hline \multicolumn{6}{|l|}{ Laboratory findings } \\
\hline Direct serum bilirubin (mg/dL) & 78 & $5.2 \pm 7.2$ & 67 & $2.8 \pm 3.9$ & $<0.000$ \\
\hline Platelets $\left(10^{3} / \mathrm{mm}^{3}\right)$ & 63 & $162 \pm 115$ & 77 & $191 \pm 109$ & 0.329 \\
\hline Piruvic transaminase-SGPT (UI/L) & 96 & $66.8 \pm 80.7$ & 113 & $147.7 \pm 384.6$ & $<0.000$ \\
\hline Blood urea nitrogen $(\mathrm{g} / \mathrm{dL})$ & 100 & $63.4 \pm 304.4$ & 98 & $25.2 \pm 100.5$ & $<0.000$ \\
\hline
\end{tabular}

The 182 confirmed cases were reported from 12 provinces of which the primarily agriculture-based provinces of Santa Fe (32\%), Entre Ríos (30\%), and Misiones (26\%) accounted for the majority of cases. The remaining cases came from provinces of Jujuy (3\%), La Pampa (3\%), Neuquén (3\%) and the six provinces (3\%) of Buenos Aires, Corrientes, Formosa, Mendoza, Río Negro and Salta.

\subsection{Clinical presentation of leptospirosis}

Confirmed cases of leptospirosis were predominantly adults (age $32 \pm 16.2$ years) and men (155 of 182, 87\%). Confirmed cases were significantly more likely to have non-specific symptoms of fever, headache and myalgias and severe manifestations such as severe complications than cases with discarded diagnosis of leptospirosis $(p<0.006)$. Meanwhile, the frequency of conjunctival suffusion was higher in confirmed cases (55\%), than in cases with discarded diagnosis of leptospirosis (43\%) $(p=0.036)$. On the contrary respiratory symptoms were more prevalent in discarded diagnosis cases $(22 \%)$ than in confirmed cases $(41 \%)(p=0,001)$ (Table 1$)$. Confirmed cases were also more likely to have higher values for direct serum bilirubin and blood urea nitrogen and lower serum transaminase values during initial clinical presentation than discarded cases $(p<0.05)$ (Table 1).

\subsection{Risk factors for leptospirosis}

Among the 105 confirmed cases of leptospirosis with information on occupation, 74 (70\%) had occupations which were associated with rural-based risk activities, such as agricultural work ( $n=42)$, dairy farming $(n=13)$, fishing $(n=9)$, abattoir work $(n=5)$, pig farming $(n=3)$, forestry $(n=2)$, apiculture $(n=1)$ and veterinary health care (1). The occupations of the 31 confirmed cases which were unrelated to rural-based activities were commerce $(n=8)$, retirement $(n=4)$, house keeping $(n=4)$, unemployment $(n=3)$, house building $(n=3)$, truck driving $(n=2)$, teaching $(n=1)$, studying $(n=1)$, sports $(n=1)$, army $(n=1)$, nursing $(n=1)$, and bakery $(n=1)$.

Univariate analysis identified risk factors for leptospirosis to be age $>30$ years, male gender, residence in an urban centre, occupation in rural settings, work-related exposure to livestock, and contact with contaminated surface water and flooding prior to the onset of illness (Table 2). In Argentina, it is common for agricultural workers to reside in small urban centres and travel to farms for work. Significant risk associations were not found between leptospirosis due to a specific presumptive infecting serogroup and potential risk exposures. Occupation in a rural setting was significantly correlated with male gender and exposure to contaminated surface water and livestock. In multivariate analyses, age $>30$ years, occupation in a rural setting, and contact with contaminated surface water and flooding were significant independent predictors of leptospirosis (Table 2).

Table 2

Risk factors for human leptospirosis, Argentina (1999-2005)

\begin{tabular}{|c|c|c|c|c|c|c|}
\hline \multirow[t]{2}{*}{ Variable } & \multicolumn{2}{|c|}{ Confirmed diagnosis of leptospirosis } & \multicolumn{2}{|c|}{ Discarded diagnosis of leptospirosis } & \multicolumn{2}{|c|}{ Odds ratio (95\% confidence intervals) } \\
\hline & No. responses & No. (\%) & No. responses & No. (\%) & Unadjusted & Adjusted $^{\mathrm{a}}$ \\
\hline Age $>30$ years & 134 & $103(77)$ & 158 & $55(35)$ & $1.87(1.17-3.00)$ & $2.16(1.05-4.41)$ \\
\hline Male gender & 182 & $158(87)$ & 167 & $115(69)$ & $2.98(1.73-5.10)$ & - \\
\hline Residence in urban centres & 144 & $72(50)$ & 155 & $115(74)$ & $2.88(1.71-4.84)$ & - \\
\hline Occupation in rural setting & 105 & $65(62)$ & 120 & $22(18)$ & $5.91(3.20-10.90)$ & $3.41(1.41-8.06)$ \\
\hline \multicolumn{7}{|l|}{ Exposure to } \\
\hline Rodents & 107 & $55(51)$ & 135 & $68(50)$ & $0.96(0.56-1.65)$ & - \\
\hline Dogs & 106 & $64(60)$ & 135 & $76(56)$ & $0.85(0.49-1.47)$ & - \\
\hline Livestock & 117 & $61(52)$ & 135 & $38(28)$ & $2.78(1.65-4.68)$ & - \\
\hline Contaminated water & 107 & $80(75)$ & 136 & $57(42)$ & $2.14(1.23-3.71)$ & $2.17(1.01-4.68)$ \\
\hline Flooding & 125 & $34(27)$ & 147 & $22(15)$ & $2.12(1.16-3.87)$ & $4.49(1.17-17.25)$ \\
\hline
\end{tabular}

a Deviance $=189.86 ; P=0.0663 ;$ d.f. $=162$. The convergence criteria were met after three iterations. 


\section{Discussion}

This study was the first evaluation of the clinical characteristics and risk factors for human leptospirosis in Argentina. As reported more than thirty years ago, Icterohaemorragie (31.3\%) remains the most seroprevalent serogroup in humans in Argentina (Cacchione et al., 1980). This serogroup was frequently isolated from rats (AAVLD, 2002) and was one of the most common to be identified in dogs, horses, sheep, swine and goats (Cacchione et al., 1975, 1980; AAVLD, 2002). Pomona (14.4\%) is frequently associated with pigs and bovines (AAVLD, 2002; Cacchione et al., 1980), while Ballum (13.7\%) has been shown to be transmitted by urban rodents (Vanasco et al., 2000a, 2003; Slack et al., 2006). Although serovar Hardjo (Sejroe serogroup) is the most prevalent in cattle, this serovar has only been isolated from healthy horses and bovines in Argentina (AAVLD, 2002; Myers and Jelambi, 1975; Myers, 1976). In this study, eight (4.4\%) of the confirmed cases had the highest MAT titres against this serovar. The high proportion of cases with agglutination titres against multiple serogroups (23.6\%) is in agreement with previous reports (Cacciapuoti, 1976; Yersin et al., 1998; Vanasco et al., 2002).

The highest number of cases occurred during warm and rainy months, where floods and leptospiral outbreaks are most frequent (Vanasco et al., 2000b, 2002, 2004; AAVLD, 2002). The only exception was the second peak observed in 2005 , which was related to a rural outbreak in the province of Entre Ríos. Differences in the number of cases reported between provinces may be related to risk of leptospirosis in these settings, but may also be due to differences in physicians' index of clinical suspicion for leptospirosis and access and referral of samples to the reference laboratory. The most common clinical presentation included non-specific symptoms of fever, headache and myalgia is in agreement with previous results in Argentina and other countries (Yersin et al., 1998; Ko et al., 1999; Vanasco et al., 2000b, 2002, 2004; Levett, 2001; Yang et al., 2005).

A high proportion of cases presented with severe complications of leptospirosis such as jaundice and acute renal insufficiency. This may reflect the tendency of clinicians to identify leptospirosis on the basis of recognizing classic severe manifestations, an observation which is frequently reported among surveillance systems in many regions worldwide (Zaki et al., 1996; Yersin et al., 1998; Levett, 2001; Sarkar et al., 2002). Although conjunctival suffusion, a hallmark clinical sign of leptospirosis (Farr, 1995; Levett, 2001), was reported in a large proportion (43\%) of cases with a discarded diagnosis of leptospirosis, this sign was significantly more prevalent among confirmed cases (55\%).

Our study had several limitations associated with national laboratory-surveillance (i.e., passive case ascertainment, referral of case samples and information to a reference laboratory, representativeness of identified cases) which could affect the findings. Moreover, the true number of cases may be actually larger than the 182 confirmed cases which we identified, since we did not obtain paired sera in all cases and the panel of serovars used in the MAT evaluation may not have included all circulating serogroups.

Male gender, urban residence and contact with livestock were strongly correlated with the occupation of the case. This may explain why these variables were significantly associated with the risk for leptospirosis in the univariate analysis but were not significant in the logistic regression model. Patients over 30 years old and in contact with contaminated water had twice the risk of becoming a confirmed case. Associations between age and case fatality from leptospirosis and between contact with contaminated water and leptospirosis were reported in a previous publication during an urban epidemic in Brazil (Ko et al., 1999; Sarkar et al., 2002). In our study, although activities associated with rural occupations remain important risk factors in Argentina, the extended contact with floods in the recent years was the most important single risk for leptospirosis.

\section{Acknowledgements}

This work was supported by the Administración Nacional de Laboratorios e Institutos de Salud (ANLIS), and the cooperative agreement between ANLIS and the Fundação Oswaldo Cruz.

\section{References}

Asociación Argentina de Veterinarios de Laboratorio de Diagnóstico (AAVLD), 2002 Informe sobre Leptospirosis en la República Argentina. Comisión Científica sobre leptospirosis. Asociación Argentina de Veterinarios de Laboratorios de Diagnóstico. Serie Enfermedades Transmisibles. Fundación Mundo Sano.

Asociación Argentina de Veterinarios de Laboratorio de Diagnóstico (AAVLD), 1994 Manual de Leptospirosis. Comisión científica permanente sobre leptospirosis.

Bharti, A.R., Nally, J.E., Ricaldi, J.N., Matthias, M.A., Diaz, M.M., Lovett, M.A., Levett, P.N., Gilman, R.H., Willig, M.R., Gotuzzo, E., Vinetz, J.M., 2003. Leptospirosis: a zoonotic disease of global importance. Lancet Infect. Dis. 3 , 757-771.

Cacchione, R., Castelli, M., Martinez, E., 1975. Encuesta serológica sobre leptospirosis humana en Argentina. Rev. Asoc. Arg. Microbiol. 7, 21-27.

Cacchione, R., Castelli, E., Saraví, M.A., Martinez, E., 1980. Difusión e importancia de la Leptospirosis animal y humana en la Argentina. Med. Vet. 61, 236-245.

Cacciapuoti, B., 1976. Co-antibodies in human leptospirosis. Boll. Ist. Sieroter. Milan 55, 495-509.

Faine S., 1982. Guidelines for the control of leptospirosis. World health Organization, Geneva (WHO offset publication 67).

Farr, R.W., 1995. Leptospirosis. Clin. Infect. Dis. 21, 1-6.

Ko, A.I., Galvao Reis, M., Ribeiro Dourado, C.M., Johnson Jr., W.D., Riley, L.W., 1999 Urban epidemic of severe leptospirosis in Brazil. Salvador Leptospirosis Study Group. Lancet 354, 820-852.

Levett, P.N., 2001. Leptospirosis. Clin. Microbiol. Rev. 14, 296-326.

McBride, A.J., Athanazio, D.A., Reis, M.G., Ko, A.I., 2005. Leptospirosis. Curr. Opin. Infect. Dis. 18, 376-386.

Myers, D.M., 1976. Serological studies and isolations of serotype hardjo and Leptospira biflexa strains from horses of Argentina. J. Clin. Microbiol. 3, 548-555.

Myers, D.M., Jelambi, F., 1975. Isolation and identification of leptospira hardjo from cattle in Argentina. Trop. Geogr. Med. 27, 63-70.

Sarkar, U., Nascimento, S.F., Barbosa, R., Martins, R., Nuevo, H., Kalafanos, I., Grunstein, I., Flannery, B., Dias, J., Riley, L.W., Reis, M.G., Ko, A.I., 2002. Population-based case-control investigation of risk factors for leptospirosis during an urban epidemic. Am. J. Trop. Med. Hyg. 66, 605-610.

Slack, A.T., Symonds, M.L., Dohnt, M.F., Smythe, L.D., 2006. The epidemiology of leptospirosis and the emergence of Leptospira borgpetersenii serovar Arborea in Queensland, Australia, 1998-2004. Epidemiol. Infect. 134, 1217-1225.

Vanasco, N.B., Rossetti, C., Sequeira, G., Sequeira, M., Calderón, G., Tarabla, H., 2000a. First isolations of leptospires serogroup Ballum serovar arborea in Argentina. Vet. Rec. 147, 246-247.

Vanasco, N.B., Fusco, S., Zanuttini, J.C., Dalla Fontana, L., Manattini, S., Prez, et al., 2002. Brote de leptospirosis humana luego de una inundación. Reconquista (Santa Fe), 1998. Rev. Arg. Microbiol. 34, 124-131.

Vanasco, N.B., Kemerer, R., Oliva, M.E., 2004. Brote de leptospirosis rural en un tambo de la provincia de Entre Ríos, Argentina, febrero-marzo 2003. Salud (i) Ciencia $12,26-31$.

Vanasco, N.B., Lottersberger, J., Schmeling, M.F., Gardner, I.A., Tarabla, H.D., 2007 Diagnóstico de leptospirosis: evaluación de un enzimoinmunoensayo en fase sólida en diferentes etapas de la enfermedad. Rev. Panam. Salud Publica 21, 388-395.

Vanasco, N.B., Sequeira, G., Dalla Fontana, M.L., Fusco, S., Sequeira, M.D., Enría, D., 2000b. Descripción de un brote de leptospirosis en la ciudad de Santa Fe, Argentina, marzo-Abril de 1998. Rev. Panam. Salud Publica 7, 35-40.

Vanasco, N.B., Sequeira, M.D., Sequeira, G., Tarabla, H.D., 2003. Associations between leptospirosis in rodents, reservoir and environmental characteristics. Prev. Vet. Med. 60, 227-235.

WHO, 2003. Human Leptospirosis: Guidance for Diagnosis, Surveillance and Control Word Health Organización- International Leptospirosis Society. NLM classification: WC 420, Malta.

Yang, H.Y., Hsu, P.Y., Pan, M.J., Wu, M.S., Lee, C.H., Yu, C.C., Hung, C.C., Yang, C.W., 2005. Clinical distinction and evaluation of leptospirosis in Taiwan-a case-control study. J. Nephrol. 18, 45-53.

Yersin, C., Bovet, P., Merien, F., Wong, T., Panowsky, J., Perolat, P., 1998. Human leptospirosis in the Seychelles (Indian Ocean): a population-based study. Am. J Trop. Med. Hyg. 59, 933-940.

Zaki, S.R., Shieh, W.J., the Epidemic Working Group at Ministry of Health in Nicaragua 1996. Leptospirosis associated with outbreak of acute febrile illness and pulmonary haemorrhage, Nicaragua. Lancet 347, 535-536. 